\title{
Heat-Structure Coupling Analysis of Harmonic Drive under Different Thermal Loading
}

\author{
Tongliang Liu ${ }^{1}$, Bindi You ${ }^{2, *}$, Peixiang Wang ${ }^{2}$, Binjiu Yang ${ }^{2}$ and Lei Liu ${ }^{3}$ \\ ${ }^{I}$ Department of Mechanical Engineering, Harbin University of Science and \\ Technology, Rongcheng 264300, China \\ ${ }^{2}$ School of Naval Architecture and Ocean Engineering, Harbin Institute of \\ Technology, Weihai 264209, China \\ ${ }^{3}$ School of Aeronautics and Astronautics, Dalian University of Technology, Dalian \\ 116024, China \\ Email:youbindi@hitwh.edu.cn
}

\begin{abstract}
Harmonic drive is a kind of new gear drives developed in the past decades, and it consists of flexspline, circular spline and wave generator. Due to thermal deformations and additional strains by the effects of temperature in harmonic drive, the mechanical property of harmonic drive is seriously influenced by its deformations. The harmonic drive mechanical characteristics are studied under the thermal loading, and heatstructure coupling is deduced in solving mathematical model of stress. The heat-structure coupling analysis of Harmonic Drive is solved, including stress and deformation law to explore new structures.
\end{abstract}

Keywords: harmonic drive, thermal coupling, strain analysis, structure deformation

\section{The Model Construction of the Harmonic Drive and the Material Parameter}

Harmonic drive is made up of the three fundamental parts which are circular spline, flexspline and wave generator. This paper focuses on the type of XB1-60 harmonic drive which simplifies the wave generator as the object, and the overall model of the harmonic drive is built up in the Figure 1 below.

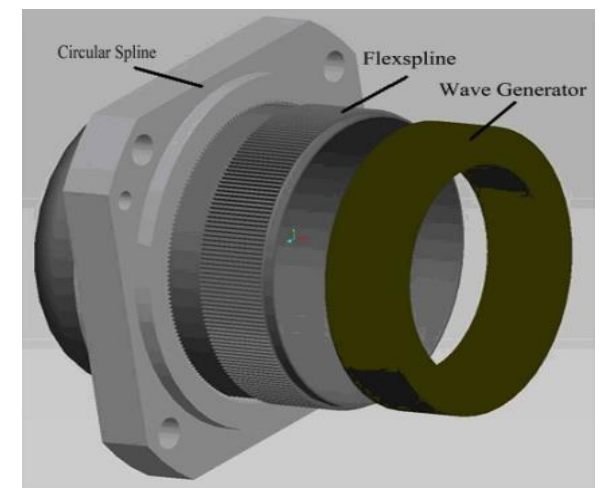

Figure 1. The Harmonic Reducer Entity Model 


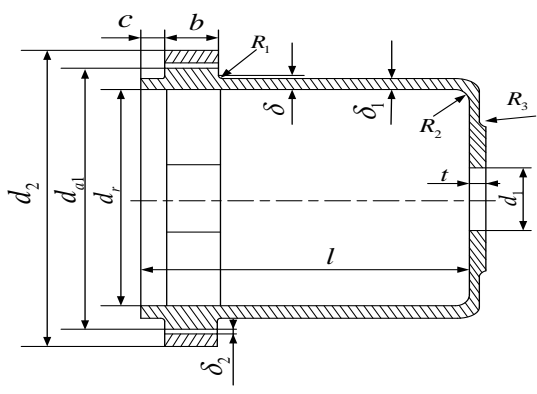

Figure 2. The Assembling Model of the Harmonic

The flexspline with the gear teeth is changed into the one without gear teeth [1] in order to be calculated easily. The model simplification will be shown in Figure 2.

The geometrical parameter is shown in Table 1. The components of material parameter in the harmonic drive [2-3] are shown in Table 2.

Table 1. The Geometrical Parameter of the Harmonic Drive

\begin{tabular}{|c|c|c|c|c|c|}
\hline Name & $\begin{array}{c}\text { Sig } \\
\mathrm{n}\end{array}$ & Number & Name & $\begin{array}{c}\text { Sig } \\
\mathrm{n}\end{array}$ & Number \\
\hline Modulus & $m$ & $0.3 \mathrm{~mm}$ & $\begin{array}{l}\text { Pressure angle of circular } \\
\text { spline }\end{array}$ & $\alpha_{2}$ & $28^{\circ} 36^{\prime}$ \\
\hline Width of flexspline & $B_{1}$ & $12.0 \mathrm{~mm}$ & $\begin{array}{l}\text { Teeth number of circular } \\
\text { spline }\end{array}$ & $Z_{2}$ & 202 \\
\hline Teeth number of flexspline & $Z_{1}$ & 200 & Width of circular spline & $B_{2}$ & $12.0 \mathrm{~mm}$ \\
\hline 'Addendum coefficient & $h_{a}^{*}$ & 0.875 & Diameter of circular spline & $D_{1}$ & $40.0 \mathrm{~mm}$ \\
\hline Tip clearance coefficient & $c^{*}$ & 0.25 & Maximal deviation & $w_{0}$ & $0.5 \mathrm{~mm}$ \\
\hline Pressure angle of flexspline & $\alpha_{1}$ & $29^{\circ} 12^{\prime}$ & $\begin{array}{l}\text { The thickness of Wave } \\
\text { generator }\end{array}$ & $h$ & $12 \mathrm{~mm}$ \\
\hline Cylinder length of flexspline & $L$ & $50.0 \mathrm{~mm}$ & Short axis of Wave generator & $b$ & $28.2 \mathrm{~mm}$ \\
\hline Wall-thickness of flexspline & $\delta$ & $\begin{array}{c}0.6625 \mathrm{~m} \\
\mathrm{~m}\end{array}$ & Long axis of Wave generator & $a$ & $28.8 \mathrm{~mm}$ \\
\hline
\end{tabular}

Table 2. Material Parameters of the Harmonic

\begin{tabular}{|c|c|c|c|c|c|}
\hline Name & $\begin{array}{l}\text { Elasticity } \\
\text { modulus }\end{array}$ & $\begin{array}{l}\text { Poisson } \\
\text { ratio }\end{array}$ & $\begin{array}{l}\text { Thermal } \\
\text { conductivity }\end{array}$ & $\begin{array}{c}\text { Coefficie } \\
\text { nt of } \\
\text { linear } \\
\text { expansion }\end{array}$ & Density \\
\hline Flexpline $\left(55 \mathrm{Si}_{2} \mathrm{Mn}\right)$ & 190GPa & 0.3 & $46.06 \mathrm{~W} /\left(\mathrm{m} .{ }^{\circ} \mathrm{C}\right)$ & $1.14 e-6$ & $6000 \mathrm{~kg} / \mathrm{m}^{3}$ \\
\hline $\begin{array}{l}\text { Circular } \\
\text { spline }(40 G r)\end{array}$ & $210 \mathrm{GPa}$ & 0.29 & $61.87 \mathrm{~W} /\left(\mathrm{m} .{ }^{\circ} \mathrm{C}\right)$ & $1.10 e-6$ & $7800 \mathrm{~kg} / \mathrm{m}^{3}$ \\
\hline $\begin{array}{l}\text { Wavegenerator( } \\
40 G r)\end{array}$ & $210 \mathrm{GPa}$ & 0.29 & $61.87 \mathrm{~W} /\left(\mathrm{m} .{ }^{\circ} \mathrm{C}\right)$ & $1.10 e-6$ & $7800 \mathrm{~kg} / \mathrm{m}^{3}$ \\
\hline
\end{tabular}




\section{The Analysis Theory of Coupling Fields}

The harmonic components go on the thermal deformation after heated. So the strain $\boldsymbol{\varepsilon}$ contains two parts [4] that they are the strain caused by the structure strain and the additional strain caused by the changes in the temperature.

$$
\boldsymbol{\varepsilon}=\boldsymbol{\varepsilon}^{m}+\boldsymbol{\varepsilon}^{t}
$$

where $\boldsymbol{\varepsilon}^{m}$ is the structure-mechanism strain, $\boldsymbol{\varepsilon}^{t}$ is thermal strain.

From the thermoelasticity, the thermal strain $\varepsilon^{t}$ can be obtained by the following formula.

$$
\varepsilon^{t}=\int_{T_{0}}^{T} \xi(T) d T
$$

where $\xi$ is the material expanding parameter, $T_{0}$ is the initial temperature.

Consider the strain in mechanism, and the mechanical stress can be expressed :

$$
\boldsymbol{\sigma}=\boldsymbol{D} \boldsymbol{\varepsilon}^{m}=\boldsymbol{D}\left(\boldsymbol{\varepsilon}-\Delta \boldsymbol{\varepsilon}^{t}\right)
$$

where $\boldsymbol{D}$ is structural stiffness matrix.

From the Mechanics Equation, we obtain

$$
\int_{\Omega} \boldsymbol{D}\left(\boldsymbol{\varepsilon}-\Delta \boldsymbol{\varepsilon}^{t}\right) d \Omega=\int_{\Omega} \boldsymbol{f}^{b} d \Omega+\int_{\Gamma_{\sigma}} \boldsymbol{f}^{s} d \Gamma
$$

where $\boldsymbol{f}^{b}$ stand for body load, $\boldsymbol{f}^{s}$ is surface load.

Consider the thermal load and mechanical load on the basis of The Principle of Virtual Displacement.

$$
\int_{\Omega}\left(\frac{1}{2}(\delta \boldsymbol{\varepsilon})^{\mathrm{T}} \boldsymbol{D} \boldsymbol{\varepsilon}-(\delta \boldsymbol{\varepsilon})^{\mathrm{T}} \boldsymbol{D} \boldsymbol{\varepsilon}^{t}\right) d \Omega=\int_{\Omega}(\delta \boldsymbol{U})^{\mathrm{T}} \boldsymbol{f}^{b} d \Omega+\int_{\Gamma_{\sigma}}(\delta \boldsymbol{U})^{\mathrm{T}} \boldsymbol{f}^{s} d \Gamma+\sum(\delta \boldsymbol{U})^{\mathrm{T}} \boldsymbol{f}^{N}
$$

where $f^{N}$ is the load vector quantity at the spot of node point.

The solving area $\boldsymbol{\Omega}$ can be concluded by the finite element. The finite element equation is obtained by the formula(5)

$$
\boldsymbol{K} \boldsymbol{a}=\boldsymbol{P}=\boldsymbol{P}_{b}+\boldsymbol{P}_{s}+\boldsymbol{P}_{N}+\boldsymbol{P}_{t}
$$

where $\boldsymbol{K}$ is structural stiffness matrix, $\boldsymbol{a}$ is generalized coordinate, $\boldsymbol{P}_{b}, \boldsymbol{P}_{s}, \boldsymbol{P}_{N}$ stand for the load vector quantity of entity force, surface load and node circle force separately, respectively.

\section{The Determination of Load of Coupling Analysis}

When the harmonic drive is suffered under the thermal environment, it is not only affected by the torque, but influenced by the space thermal [5-7]. 


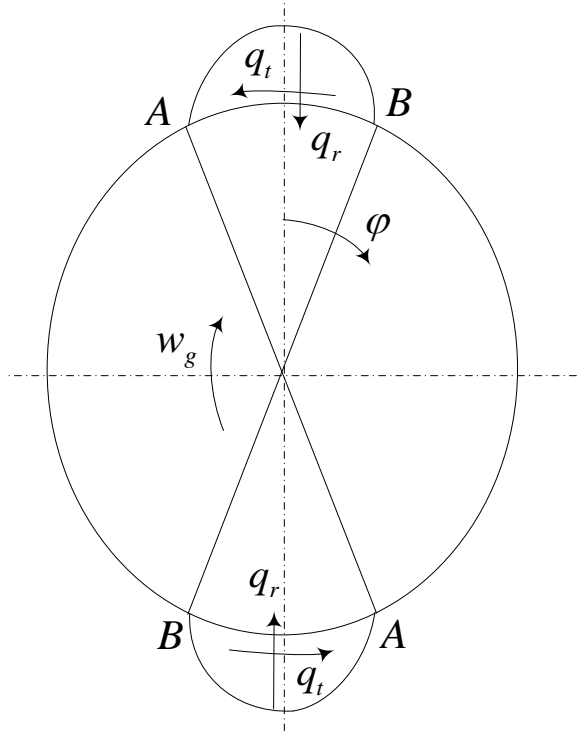

Figure 3. The Load Distribution of the Flexspline with Load

According to the literature [8], there may exist the following relation between the maximal tangential load and the torque in the flexspline in the area of meshing, as the Figure 3 shows.

$$
\begin{gathered}
q_{t \max }=\pi T\left(2 \gamma B_{1} D^{2}\right) \\
q_{t}=q_{t \max } \cos [\pi(\varphi-\gamma) / 2 \gamma]
\end{gathered}
$$

where $T$ is the torque on the Flexspline, $\gamma$ is half of the meshing wrap angle, $\gamma=0.5 \beta, D$ is the Pitch circle diameter of Flexspline, $q_{t}$ is tangential load.

The temperature figure corresponding to the circular spline and wave generator are shown in Table 3. When it comes to analysis, each of the outer surfaces of parts should be put focus on separately.

Table 3. The Harmonic Drive Temperature Loads

\begin{tabular}{crrrrrrr}
\hline Numer of times & 1 & 2 & 3 & 4 & 5 & 6 & 7 \\
\hline $\begin{array}{c}\text { Temperature of } \\
\text { Flexspline } /{ }^{\circ} \mathrm{C}\end{array}$ & 60.0 & 40.0 & 20.0 & 0.0 & 20.0 & 40.0 & 60.0 \\
$\quad \begin{array}{c}\text { Temperature of } \\
\text { Circular spline } /{ }^{\circ} \mathrm{C}\end{array}$ & 44.2 & - & - & 3.1 & 15.2 & 31.5 & 45.3 \\
$\quad$ Temperature of & - & -16.7 & 12.4 & 16. & 23.6 & 28.7 & 30.2 \\
Wave generator $/{ }^{\circ} \mathrm{C}$ & 27.5 & -1.1 & & & & & \\
\hline
\end{tabular}

\subsection{The Strain Analysis of the Flexspline}

When working on the track, the harmonic drive can be affected by the rated moments and space thermal load [9-10]. The components of flexspline are the best choices to facilitate observation. When temperature reaching $40{ }^{\circ} \mathrm{C}$, its stress and aberration nephogram are shown as follows. 


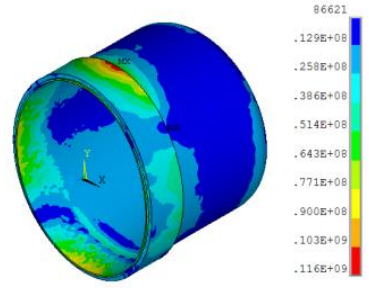

(A)Stress Nephogram

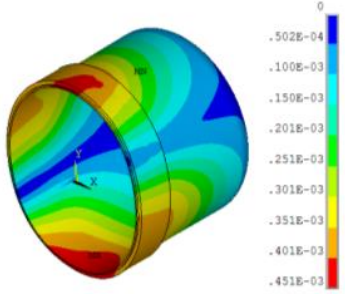

(B)Aberration Nephogram

Figure 4. The Stress and Aberration Nephogram of Flexspline under $\mathbf{4 0}$ Centigrade

The maximal equivalent stress that occurs on the meshing situation between flexspline and circular spline from the chart under the condition of temperature loading $\left(40^{\circ} \mathrm{C}\right)$ and rated torque can be observed easily. And the maximum stress is $116 \mathrm{MPa}$. As the increase of the temperature loading, the harmonic drive strain and the distribution of deformation also change. The harmonic drive stress peaks under the influence of different temperature are shown in Table 4.

Table 4. The Maximal Equivalent Stress as the Temperature Varies

\begin{tabular}{cccccccc}
\hline $\begin{array}{c}\text { Flexspline } \\
\text { temperature } /{ }^{\circ} \mathrm{C}\end{array}$ & -60 & -40 & -20 & 0 & 20 & 40 & 60 \\
\hline $\begin{array}{c}\text { Maximal } \\
\text { stress/MPa }\end{array}$ & 86. & 85. & 90. & 92. & 98. & 116 & 140 \\
\hline
\end{tabular}

In order to facilitate observation, the table is converted into a graph:

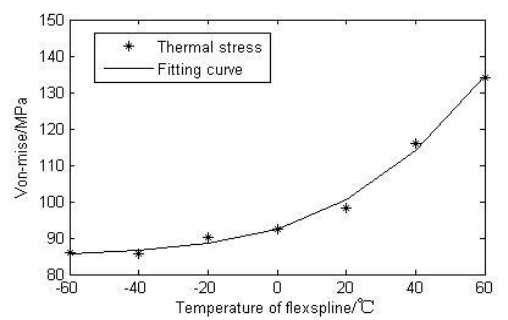

Figure 5. The Maximal Equivalent Stress as the Temperature Varies

From the Figure 5, under the low temperature, it has little effect on the harmonic drive. However, when the temperature is more than $20{ }^{\circ} \mathrm{C}$, the maximal equivalent stress increases significantly with the increase of the temperature.

When harmonic drive is suffered external loads, dangerous section [11] mainly focuses on the situation of rear face and the hole of output shaft before the gear ring. For the reason, this paper extracts the stress from the front gear ring (section I), the rear face (section III), and the inner surface (sectionIV). The situation of individual section follows as Figure 6. 


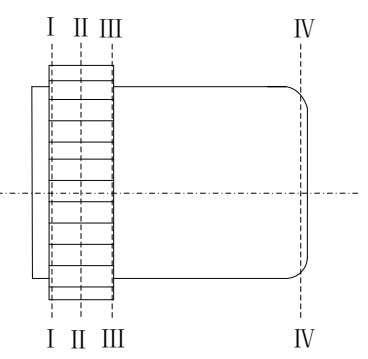

\section{Figure 6. Division of Flexspline}

The rear face of flexspline (section III) has the largest strain, ranging from $105^{\circ} \mathrm{C}$ to $115^{\circ} \mathrm{C}$. And the strain increases as the temperature load goes up. When the temperature reaches minus 60 centigrade, the maximal strain is $122.6 \mathrm{MPa}$.The maximal strain of the gear ring front face occurs in the areas of 15 to 25 centigrade or 195 to205 centigrade. As the increase of the temperature loading goes up, the strain ranges from $78.4 \mathrm{MPa}$ to 116.1MPa. The internal surface hole of output shaft's stress belonging to the flexspline still fundamentally varies in cosine. Under the low temperature, the stress fails to vary remarkably. And under the relatively higher temperature, the stress increases as the temperature goes up.

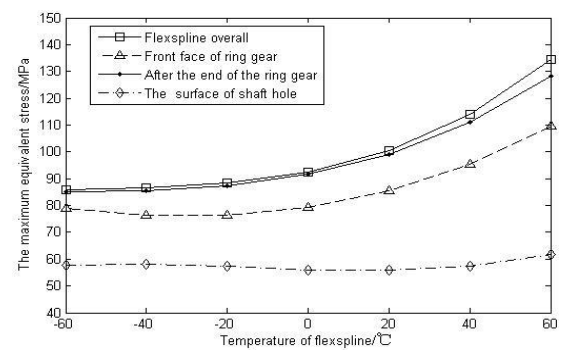

Figure 7. The Maximal Equivalent Stress of the Flexspline under the Variedfrom-Temperature

As the temperature load rises, the maximal equivalent stress of the individual sections also rises. The gear ring belonging to the head face changes relatively remarkable, which has the greatest influence on the gear ring meshing forces of the circular spline and flexspline.

\subsection{The Analysis of Deformation}

The deformation of the flexspline is made up of two parts: One is from the influence of the moments, and includes wave generator-flexspline that meshes deformation by the contact deformation caused by the Cam Type contact meshing with flexspline meshing. And when it comes to the other, because of the impact of the temperature, each of components may have additional deformation. It is obvious to find the deformation rules of the flexspline in the harmonic drive by the definite element equivalent. As in Figure 8(b), when the temperature reaches 40 centigrade, the harmonic drive deforms entirely under the rated loading. 


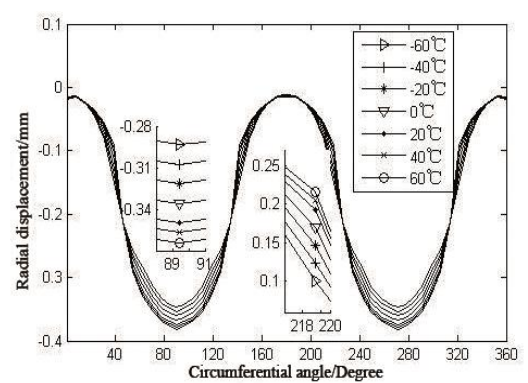

(a)Radial displacement

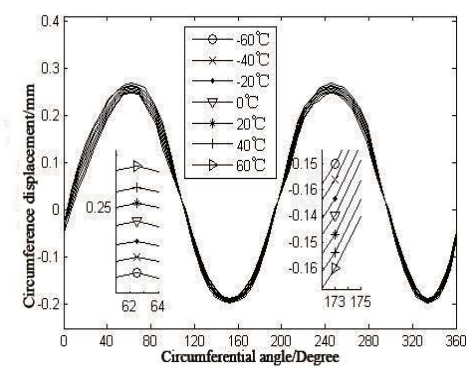

(b)Circumference displacement

\section{Figure 8. The Varied-form-Temperature Curve Chart of the Flexspline of Each Directions}

In the light of the deformation of the flexspline under the hot environment and the idealized condition, the distinctions are obvious. The radial displacement peak still exists in the long axis areas of the wave generator. Additionally, the temperature shows the greatest distinction in the area of short axis on the wave generator. The influence is less remarkable than that in the areas of long axis. The circular displacement peak exists in the areas of the middle areas of the long and short axis. The temperature, to the long and short axis of the wave generator, has effect on the deformation of the displacement. Under the different temperatures, the axis displacement peaks and the deformation can hardly vary.

In order to the flexspline entire deformation caused by the thermal load, the flexspline deformation alongside the axial gear is analyzed. For instance, under the loading at the temperature of 40 centigrade, the tube length is divided into 21 groups along axial direction and respectively extracts the maximal deformation of the gear, and the circumference maximal deformation.

$$
\begin{gathered}
w=2.056 \times 10^{-7} x^{4}-1.915 \times 10^{-5} x^{3}+5.024 \times 10^{-4} x^{2}-7.62 \times 10^{-3} x+0.3367 \\
v=8.677 \times 10^{-5} x^{2}-8.914 \times 10^{-3} x+0.3015
\end{gathered}
$$

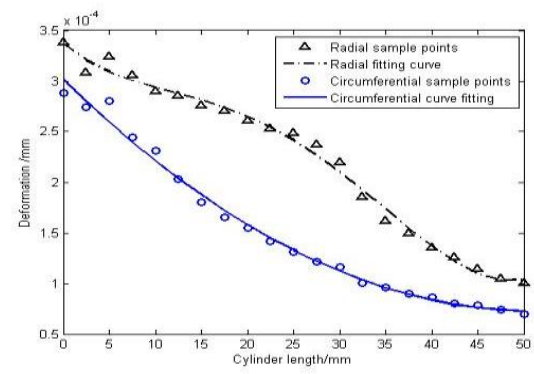

Figure 9. The Displacement of the Axis under 40 Centigrade

From the above, the maximal displacement in the areas of the gear ring with the radial (UX) direction constants fundamentally. The variation of displacement on the slipper body changes a lot and the linear tendency does not exist any more.

Under the condition of 40 centigrade, the gear body ranges from negative $90^{\circ} \mathrm{C}$ to $90 \mathrm{~s}$, and may have the deformation of radial and axis. As the Figure 10 shows, the nearer flexspline comes, the larger radial deformation is. But it doesn't vary equably any longer. Two spots of obvious hollows that they indicate the deformation show in linear distribution. And from the picture(b), the circumference deformation does not vary from 
the linear relationship any longer. Besides, the nearer the circle comes, the more deformation it has.

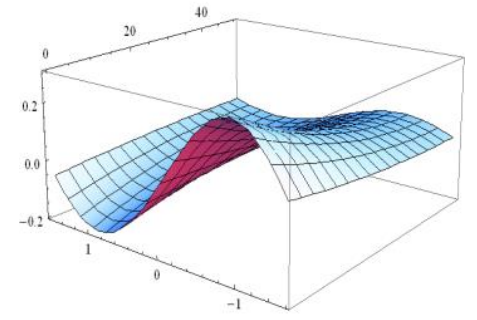

(A)The Radial Deformation

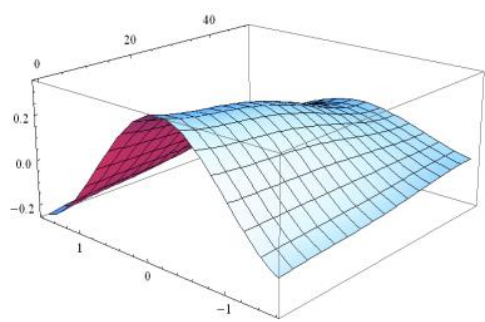

(B) The Circumference Deformation

Figure 10. Displacement of the Axis When the Temperature is 40 Centigrade under the Working Condition

\section{Conclusions}

The harmonic drive mechanism suffered by the torque load conditions and mechanical properties is studied, including different loads flexspline stress distribution along the circumferential direction. While the use of polynomial fitting function flexspline overall deformation function is analyzed. By comparative analysis, the higher the temperature it is, the greater the maximum equivalent stress flexspline it shows. The front and the rear end face of the ring and the stress amplitude variation are relatively larger. Also, the stress of output shaft is a relatively small hole in the surface of the stress variation. With the higher the temperature of all directions, the flexspline deformation shows an increasing trend, but is no longer a linear distribution.

\section{Acknowledgements}

This paper is based on the Projects (Approval Nos. 51205079 and 11402044) supported by National Natural Science Foundation of China, and the Projects (HIT. NSRIF. 2015110) supported by Natural Scientific Research Innovation Foundation in Harbin Institute of Technology, and supported by the advanced research project (51320030201) of "Twelfth-Five-Year-Plan" of equipment and China Postdoctoral Science Foundation funded project (2013M541358), and Supported by Science \& Technology on Reliability \& Environmental Engineering Laboratory (KHZS20143003).

\section{References}

[1] V.S. Polenov, "Investigation of the stress-strain state of flexible elements in wave drives Soviet Applied Mechanics", 1981: 34-39.

[2] K.S. Jeong, D.G. Lee and S.H. Oh, "Development of the composite flexspline for a cycloid-type harmonic drive using net shape manufacturing method [J]", Composite structures, 1995: 557-565.

[3] A.A. Tronin, "Satellite thermal survey-a new tool for the study of seismoactive regions [J]", International Journal of Remote Sensing, 1996: 1439-1455.

[4] Y. Kiyosawa, M. Sasahara and S. Ishikawa, "Performance of a strain wave gearing using a new tooth proile Source [J]", Materials and Design, 2010: 87-92.

[5] E.A. Thornton and R.S. Foster, "Dynamic response of rapidly heated space structures [J]", Progress in Astronautics and Aeronautics, 1993: 451-451.

[6] K.B. Shin, C.G. Kim and C.S. Hong, "Thermal distortion analysis of orbiting solar array including degradation effects of composite materials [J]", Composites Part B: Engineering, 2001: 271-285.

[7] M. Murozono, E.A. Thornton, "Buckling and quasistatic thermal-structural response of asymmetric rolled-up solar array [J]", Journal of spacecraft and rockets, 1998: 147-155.

[8] O. Kayabasi and F. Erzincanli, "Shape optimization of tooth profile of a flexspline for a harmonic drive by finite element modeling [J]", Materials and Design, 2007: 441-447.

[9] S. Tizzi, "Numerical procedures for thermal problems of space antennae shells [J]", Acta Astronautica, 
2004: 103-114.

[10] B. Bigdeli, "A Finite Element Thermal-Structural Analysis of the Mast of the International Space Station//AIAA/ASME/ASCE/AHS/ASC Structures, Structural Dynamics, and Materials Conference and Exhibit", 41st, 2000.

[11] P. Folęga and G. Siwiec, "Numerical Analysis of Selected Materials for Flex- splines [J]", Archives of Metallurgy and Materials, 2012: 185-191. 
International Journal of Control and Automation Vol.8, No.11 (2015) 